\title{
Role of Sensual Image in Scientific Generalisation
}

Rafaehl' Rahmatullin, ${ }^{\dagger}$ Ehl'vira Semenova, ${ }^{\dagger}$ Anatoliy Stoletov, ${ }^{+*}$ Timur Nazarov, ${ }^{\dagger}$ Il'giz Muhamadeev Muhamadeev, ${ }^{\dagger}$ Liliya Goremykina, ${ }^{\dagger}$ Rafis Ziyazetdinov, ${ }^{\dagger}$ Aleksandra Krul' ${ }^{\dagger}$ and Lenara Semenova ${ }^{\dagger}$

\section{Abstract}

The method of generalisation widely used in scientific research is a variant of the similar logical method. Generalisation in different scientific areas has its own specifics, but in fundamental knowledge, it allows to create general concepts. We explore generalisation in scientific knowledge, focusing on the peculiarities of the formation of general concepts and the role of sensory image in their functioning in scientific theory and the retranslation of scientific knowledge. Scientific, philosophical, religious, literary texts were studied and compared to determine the essence and characteristic features of the generalisation method. Subsequently, the information extracted from these texts was systematised using the methods of similarity and difference. The resulting material based on analogy served as the basis for the conclusion. The method of concomitant variations turned out to be necessary for establishing the dependence of scientific results on changes in research conditions, which was done on the example of the evolution of generalising images in the field of atomic physics. During generalisation, it is necessary to search for a successful image of a general concept, which is important for understanding its meaning. The image obtained as a result of generalisation of scientific knowledge is an essential semantic unit of a scientific retranslation. General concepts contain generalised images of classes of objects and thus configure the scientific picture of the world. They perform not only a representative but a communicative function in the process of reproducing of scientific knowledge both within science and in society. While scientific knowledge becomes more and more abstract, a sensual image makes it possible to detect relationships that are not accessible to a rational level of knowledge. It also facilitates the transferring of knowledge in learning.

Keywords: Generalisation, Science, Representation, Image, General Concept, A Retranslation of Scientific Knowledge

\footnotetext{
${ }^{\dagger}$ Federal State Budgetary Educational Establishment of Higher Education «Bashkir State Agrarian University»

${ }^{*}$ Corresponding Author, Email: anatoliy.stoletov@yandex.ru, aistoletov@gmail.com

C2019 Rahmatullin et al. This is an Open Access article distributed under the terms of the Creative Commons Attribution License (http://creativecommons.org/licenses/by/2.0), which permits unrestricted use, distribution, and reproduction in any medium, provided the original work is properly cited.
} 


\section{Introduction}

The logical operations of despecification and generalisation, associated with abstraction and transition from the specific properties of individual objects to their common properties are widespread in scientific methodology (Mallon, 2018; Mason, 2018; Żenczykowski, 2018; Bonzio et al., 2019; Fernández, 2019; Ram et al., 2019). Scopus database gives several hundreds of thousands of publications at the request of the term "generalisation" in all research areas. Accordingly, the content of this concept has its own characteristics in various scientific fields. For example, in medicine, biology, microbiology, and agricultural sciences, generalisation is understood as the process of spreading a focus of pain, infection, a tumor on an entire organ, part of the body, organism or ecological system (Gabdrakhimov et al., 2018; Ivanov et al., 2018; Rakhimov et al., 2018). In cartography, this term is used to refer to the operation of selecting and summarising geographic objects to mark them on a map (Phalke \& Özdoğan, 2018). In psychology, it implies an associative transfer of a painful experience or phobia from one object to another (McGlade et al., 2019). Even though more often generalisation is used in the natural sciences and mathematics, it plays a significant role in social research (Thorpe \& Figge, 2018; Townsend \& Ellis-Young, 2018; Lukmanov et al., 2018) and the humanities (Stoletov, 2016; Mulder, 2018).

The term is absent in some philosophical dictionaries. While in Russian, both "generalisation" and "despecification" exist as somewhat distinct terms, the English tradition denotes what appears as two different operations simply as "generalisation". We found the definition of generalisation as a process of arriving at a general notion or concept from individual instances (Dictionary of Philosophy, 1942). Stanford Encyclopedia of Philosophy contains the article about generic generalisations considering mostly logical, semantical and linguistic aspects (Leslie \& Lerner, 2016). Generalisation as a general scientific method was analyzed in two dissertation research projects written by Rahmatullin (2000) and Murtaeva (2015). Both authors, considering generalisation in an epistemological context, suggest that this term should be defined as a representation of a particular class of objects via a significant individual one. We will adhere to this understanding of the term.

Several authors, writing as early as in the eighteenth century, describe the process similar to generalisation, even though they did not use this term. George Berkeley and David Hume, who investigated the nature of knowledge, revealed the presence of this phenomenon, which is closely related to the operation of abstraction. Berkeley in "A Treatise on the Principles of Human Knowledge" (Berkeley, 2016) writes about the ability of the human mind to create images that can represent entire classes of homogeneous objects. He sees that the operation of abstraction has a continuation: if an abstraction involves the formation of a general concept, then its continuation arises in connection with perception and retranslation of this concept. While, as noted above, Berkeley does not use the term "generalisation", but it follows from the examples he cites that he writes precisely about this very operation. For example, analysing such a concept as a person, he notices that although it does not imply that colour of the skin or growth is obligatory, we cannot imagine a person to be colourless and not having a certain height. In the same way, he writes, the idea of a triangle does not contain an indication of the dimensions of its angles and sides, but we always represent it as a specific geometric shape with a certain amount of angles and sides. According to Berkeley, the common concepts important for communication between people (person, triangle, movement, line, etc.) are always tied to their sensual shell - a particular image.

Hume (2007) continues to develop Berkeley's constructive epistemology. From his point of view, the general idea of the line, despite all our abstractions, when it appears in mind, has an exact degree of quantity and quality. No 
impression can be represented in mind without being determined in its degrees of both quantity and quality. Next, Hume concludes by explaining the mechanism of generalisation that the image in our mind is only an image of a particular object, although its use in our reasoning is as if it were universal. He explains this peculiarity of our mind by the fact that many images, belonging to the same class, arise in consciousness when a concept is formed by abstraction. However, when a person perceives a word denoting a class of objects, their mind takes the most familiar individual image of the object which belongs to this class out to the forefront(Norton \& Norton, 2000). Distinguishing between despecification and generalisation is uncommon in both Russian and international research. We, however, intend to show what distinguishes generalisation explicitly as a method and emphasise its role in scientific knowledge, which is associated with comprehending more complex and abstract levels of the Universe ever. This comprehension reinforces the need to apply the method in scientific research.

The introduction sets up a rationale for the study. The results section discusses the sensual basis of generalisation, the role of sensory imaging in scientific thinking. In this section, we compare generalisation in scientific and nonscientific fields of knowledge. Then in the discussion section we discuss the special importance of sensory imaging arising during generalisation for scientific communication and retranslation of scientific knowledge. Finally, the conclusion describes the main implications of the study. The following section discusses the methods that were deployed for this research.

\section{Methods}

The principles of integration of sensual and rational, individual and general, determinacy of scientific knowledge by the sociocultural process are the methodological basis of the study. The works from the history of philosophy and science, literary texts, researches of imagery in modern epistemology, psychology and physics was the material of the study. Scientific, philosophical, religious, literary texts were studied and compared to find out the essence and characteristic features of the generalisation.

Subsequently, the information extracted from these texts was systematised using the methods of similarity and difference. Based on analogy, the resulting material served as the basis for the conclusions. The method of concomitant variations turned out to be important for establishing the dependence of scientific results on changes in research conditions, which was done on the example of the evolution of generalising images in the field of atomic physics.

We should note that generalisation in science is a variant of the logical method of generalisation. Therefore, it complies with the general algorithm for applying this method. This algorithm is associated with the operation of including the concept under study in the scope of the more general concept. However, during generalisation, it is necessary to search for a successful image of a general concept, which is vital for understanding its meaning. This is an additional condition that distinguishes generalisation in scientific research from a logical operation of generalisation.

\section{Results}

We consider generalisation a kind of despecification. It is known that a generalisation is usually understood as the logical operation of transition from a single concept to a general one, and from a less general to a more general concept. However, there is a well-founded opinion that a generalisation is possible at the sensory level of knowledge. In some psychological studies (Gibson, 1972; Zinchenko, 1990; Bruner, 1991) generalising possibilities of figurative representations are based on a large amount of factual material. In this case, the image of an individual object appears as an invariant of generalising the entire class of objects. It turns out that even people who do not own scientific thinking are capable of generalisation carried out by them at the sensual level of comprehending the world. A generalisation at the sensory level of knowledge is the evolutionarily established ability of the human psyche to single out the constant 
characteristics of objects, allowing them to form clusters of homogeneous objects (O'Connor, 2017). Generalisation, carried out with the help of extralogical operations, is more commonly known in psychological studies under the term "categorisation". For example, the retina of the human eye can perceive more than 3 million colours, but at the level of consciousness, we usually distinguish no more than 25 colours, each of which allows to combine tens of thousands of varieties of electromagnetic waves of the light spectrum into one category (cluster) (O'Connor, 2015).

The essence of generalisation can be understood better if we compare it with typification in the field of art. Typification underlies the creative process associated with the creation of an artistic image. Maxim Gorky (Gor'kij, 1953) described the general algorithm of this phenomenon. Gorky, analysing his own literary experience, notes that the work of a writer reminds him of that of a scientist: if a scientist accumulates information about a subject area of research by doing dozens and hundreds of experiments with the aim of obtaining a generalised result, the writer does almost the same: highlights feats, heroic deeds of large masses of people, which are then summarised in an artistic image of a literary character (Gor'kij, 1953).

By image, we mean such a form of representation of reality which is a "complex of sensory signals isomorphic to the content of the original object and subjectively experienced as the object itself outside the psyche" (Rahmatullin, 2017: 63). Such a definition allows:

- to limit the scope of this concept to mental phenomena, to distinguish an image from material objects (drawing, photograph, project, model and others);

- to distinguish between an image and such mental phenomena as sensation, emotion, passion, and others, which are not isomorphic to their denotation, that is, do not have structural conformity with it;

- to distinguish an image from theory, a description of an object, a hypothesis, which can structurally correspond to the object, but represents the types of logically structured knowledge, whereas the image belongs to the sphere of the sensual;

- not to identify an image with a sign, a symbol and other similar representatives. An image is always intentional and is perceived by a person in the form of an objectively existing object if it is outside the special reflection.

Belinskij (1940) suggested evaluating the quality of a literary image by its ability to reflect the typical features of a certain group of people. He wrote that there is no creativity without "typism". In his work devoted to the poetry of Mikhail Lermontov Belinsky directly indicates that in a highly artistic work, each image must embody a large number of persons belonging to the same genus. In his opinion, a representative image is a synthesis of general and individual characteristics. Therefore, each character in a work of fiction created by a talented writer is an expression of typical attributes and is perceived by a reader as a "familiar stranger" (Belinskij, 1940: 32). It turns out that typification is a way of expressing an invariant using a variant. Describing the image that an artist creates, $\mathrm{N}$. Belyaev writes that it, being the original concise image of the prototype, is something concrete, but something special that turns out to be typical is imprinted in this particular image (Belyaev, 2007).

Comparing generalisation with typification reveals another characteristic of this operation, which is important for determining its essence. As is known, the emergence of an artistic image is always the result of creativity, conscious construction of a bright type, which focuses the attention on those qualities that the artist considers important. This result becomes the part of the artistic picture of the world of both the author and the recipient, shaping their personal worldview. (Stoletov, 2005:72-73).

Consequently, the artistic image is the unity of the sensual and the rational. However, images obtained as a result of scientific creativity have 
the same quality. For example, the images of the planet, stars, molecules, cell division are the result of not only observation but also the logical operations of analogy, systematisation, inductive and deductive conclusions, proof and refutation. At the same time, new significant results obtained as a result of scientific research entail the correction of images of the scientific picture of the world in particular science areas or the science generally. Thus, Albert Einstein's (2018) comprehension of the experiment by Albert A. Michelson and Edward W. Morley (Masreliez, 2015), which measured the speed of light, have led to a fundamental change in the image of space as a void, replaced by the image of space as a material medium, changing following the mass of the object placed in it. In the same way, the image of an atom as the form of plum pudding with electrons embedded in it, proposed by John J. Thomson, is replaced in 1911 by Ernest Rutherford (Shoup, 2018) with the figurative representation of an atom as the form of a system of negatively charged electrons rotating around a positively charged nucleus.

It is known that this change occurred after Rutherford had evaluated the results of a number of the gold foil experiments on the dispersion of alpha particles (Suzuki, 2016) performed by Hans Geiger and Ernest Marsden (Lawson, 2016). Experiments repeated by Rutherford with a change in experimental conditions (replacing gold foil with aluminium, copper, silver and platinum) gave similar results. This allowed him to create a new image of the atom (Webber \& Davis, 2012). So, we can see that the images appearing in science as the representative of a large aggregate of objects represent not only the unity of the general and the individual but also the synthesis of the rational and the sensual. So the direct subjective vision of the world is fused organically with theoretical ideas, principles and categories in the world outlook's visual image. It is the nature of ontologised representations of the scientific picture of the world. In addition to the ability representing a class of objects, two more interrelated functions of the image are essential as a means of generalising scientific knowledge for epistemology. These are semantic and communicative functions of the image.

There was a growing interest in images and model representations functioning in science in the period from 1950 to 1980. In our opinion, this was primarily due to the unprecedented growth of mathematisation of science, which, in turn, exacerbated the issue of understanding the meaning of the abstract theories abstracted to the limit. The appearance of a new epistemological category, which was called the "scientific picture of the world", belongs to this period. Its peculiarity was the desire to express the most generalised knowledge of the fields of scientific research in a visual form. The purpose of the procedure was to allow far more people to gain easier access to scientific knowledge in culture. We associate using imagery as a means of understanding abstract knowledge with the presence of common for all people mental and physiological patterns of information perception, which have been formed for thousands of years in the process of phylogenesis. The language of images is a kind of universal language understandable for a person. Therefore, attempts to transform scientific theoretical knowledge into a clear picture can be viewed as a reduction of a complex language to a simpler one. In this context, the images of the scientific picture of the world appear as a necessary semantic component of the language of science. Considering the most effective methods of organising the training of air traffic controllers, he concludes that in many cases, teaching using visual aids is more effective than using verbal messages (Holt, 1964). Modern research shares the importance of visual images in learning (Miyatsu et al., 2019).

\section{Discussion}

The problem of understanding is acutely felt in communicative processes in the sphere of intrascientific and intracultural functioning of complex scientific theories. Richard Feynman showed how the understanding of the laws of quantum mechanics occurred through imaginative thinking (Feynman, 2011). Most often, the need to transform abstract knowledge into visual form arises when it is translated into 
the educational environment. Therefore, in many respects, the work of a teacher consists in his ability to transform complex abstract-logical constructions into simple visual representations which students are able to understand (Rahmatullin, 2000). Often this requires no less effort than the creation of theory.

Russian psychologist Vladimir Zinchenko considers generalisation in the context of exteriorisation, which is the objectification of the mental, its projection into the external sensual world in the form of an image that is convenient to use when transmitting scientific information to the addressee. This process of transition from thought to image is essential for understanding the functioning of scientific knowledge in culture (Zinchenko, 1990).

We do not think that the use of images in scientific communication should be minimised despite Plato's idea about the impossibility of the objective expression of the essence with the help of figurative representation (McCabe \& Castel, 2008). Under the principle of fallibilism, scientific theory should not claim to be absolute objectivity due to the fact that it does not take into account all the facts affecting the subject of the research! The effectiveness of scientific communication is determined by the ability of its means to convey the meaning of a particular concept. This becomes clear if we compare scientific communication with similar processes taking place in the extra-scientific field. The mythological image of Hercules, the artistic image of Hamlet, the religious images of Jesus Christ or Krishna are the result of a person's creativity trying to express thoughts and values, which are important to people, in the way that they can understand.

These are not photographs claiming to be an exact copy of objective reality, but means of transmitting meaning used along with verbal language. The same quality is possessed by scientised images, which change along with changes in scientific concepts. The image of an atom presented by Democritus in the form of an absolutely indivisible particle or its image by Lucretius Kar in the form of randomly moving dust particles corresponded to the level of physical knowledge of the times of Antiquity (Du Sautoy, 2016). This image conveyed the meaning of this very knowledge.

The evolution of the image of the atom in the early twentieth century from Thomson to Rutherford, and from the latter to the image of Bohr-Rutherford corrected by Niels Bohr, accompanied the changes in the atomic theory of that time. In scientific knowledge, the image follows the theory and is only one of the means of its expression along with graphs, diagrams, formulas and metaphors.

\section{Conclusion}

To sum up, we consider generalisation as a general scientific operation of representing a certain class of objects necessarily using the sensual image of a characteristic individual representative of its object's class. The generalisation is associated with the logical operation of abstraction: the image obtained as a result of the generalisation of scientific knowledge is the carrier of meaning, an important semantic unit of the verbal expression of a general concept. The combination of such images is included in the general scientific picture of the world or the pictures of a certain field studied by science (specific scientific, local pictures of the world).

Generalisation differs from abstraction and despecification by the existence of the result of a mental operation in a figurative form, bearing references to the sensory experience of the subject. Thus, generalisation combines the rational and the sensual, and their unity creates a form of knowledge that serves as a combination of the theoretical and practical spheres of scientific knowledge. The result of generalisation is similar to the creation of an artistic image in the course of the typification of real-life objects. It is included in the picture of the world of the subject of knowledge and forms its world outlook as well as the artistic image constructed during the course of generalisation.

Images obtained as a result of generalisation are important components of intrascientific and intracultural communication. They perform a hermeneutic function in it. The importance of 
generalisation increases, allowing scientific knowledge to be brought closer to what is perceived by the subject - the sensual image. It is due to the growth of the abstract nature of scientific knowledge and the increasing complexity of the nature of knowable objects. This creates the possibility both of detecting relationships between objects that fall outside the field of view of rational thinking, and learning and transmitting this knowledge to other subjects.

\section{References}

Belinskij, V. G. (1940). M. YU. Lermontov: Stat'i i recenzii. Leningrad: Hudozhestvennaya literatura (In Russian).

Belyaev, N. I. (2007). Obraz cheloveka v izobrazitel'nom iskusstve: individual'noe itipichnoe. Vestnik Orenburgskogo gosudarstvennogo universiteta, 7(71), 175-179 (In Russian).

Berkeley, G. (2016). A Treatise Concerning the Principles of Human Knowledge (Classic Reprint) (pp. 438). Fb\&c Limited.

Bonzio, S., Loi, A., \& Peruzzi, L. (2019). A Duality for Involutive Bisemilattices. Studia Logica, 107(2), 423-444.

Bruner, J.S. (1991). The Narrative Construction of Reality. Critical Inquiry, 18(1), 1-21.

Dictionary of Philosophy. (1942). Ed. by Dagobert D. Runes. Available at: http://www.ditext.com/runes/index.html (Access data: 06.04.2019)

Du Sautoy, M. (2016). The great unknown: seven journeys to the frontiers of science. Penguin.

Einstein, A. (2018). The Collected Papers of Albert Einstein, Volume 15 (Translation Supplement): The Berlin Years: Writings \& Correspondence, June 1925-May 1927. Princeton University Press.

Fernández, E. (2019). Habit and Generalization. Chinese Semiotic Studies, 15(1), 153-163.

Feynman, R. (2011). What is science? Resonance, 16(9), 860-873.
Gabdrakhimov, K. M., Khayretdinov, A. F., Sultanova, R. R., Konashova, S. I., Konovalov, V. F., Sabirzyanov, I. G., Gabdelkhakov, A. K., Isyanyulova, R. R., Martynova, M. V., \& Blonskaya L. N. (2018). Reproduction of Stable Pine Forests in the Southern Urals. Journal of Engineering and Applied Sciences, 13, 64946499.

Gibson, J.J. (1972). A theory of Direct Visual Perception. In J. Royce, W. Rozenboom (Eds.). The psychology of Knowing. New York: Gordon \& Breach.

Gor'kij, M. (1953). O literature. Moscow: Sovetskij pisatel' (In Russian).

Holt, R. R. (1964). Imagery: The Return of the Ostracized. American Psychologist, 19, 254-264.

Hume, D. (2007). An enquiry concerning human understanding and other writings. Cambridge University Press.

Ivanov, A. I., Andreeva, A.V., Skovorodin, E. N., Shaimukhametov, M. A., Altynbekov, O. M., Sultangazin, G. M., Galieva, Ch. R., Urmanov, I. M., Khakimova, A. Z., \& Nikolaeva, O. N. (2018). Anaerobic Microflora Impacton Pathomorphogenesis of Swine Dysentery. Journal of Engineering and Applied Sciences, 13, 8796-8802.

Lawson, R. S. (2016). Evolution of Nuclear Medicine Physics in the UK. In A History of Radionuclide Studies in the UK (pp. 33-38). Springer, Cham.

Leslie, S.-J., \& Lerner, A. "Generic Generalizations". The Stanford Encyclopedia of Philosophy (Winter 2016 Edition). Available at: https://plato.stanford.edu/archives/win2016/e ntries/generics/ (Access data: 06.04.2019).

Lukmanov, D. D., Habirov, G. A., Kushubakova, B. K., Akhmadieva, A. F., Ismagilov, K. R., Fanisov, R. F., Iskuzhina, G. R., Valieva, G. R., Atazhanova, A. A., \& Yumaguzhina, J. R. (2018). Private Land Ownership Development and Investments in the Agrarian Sector of Emerging 
Economies. Journal of Engineering and Applied Sciences, 13, 8760-8767.

Mallon, R. (2018). Constructing race: racialization, causal effects, or both? Philosophical Studies, 175(5), 1039-1056.

Mason, J. (2018). Generalizations, Cultural Essentialism, and Metaphorical Gulfs. Dao, 17(4), 479-497.

Masreliez, C. J. (2015). The Progression of Time New ideas in physics. Russian Academy of Sciences, Saint Petersburg.

McCabe, D. P., \& Castel, A. D. (2008). Seeing is believing: The effect of brain images on judgments of scientific reasoning. Cognition, 107(1), 343-352.

McGlade, A. L., Zbozinek, T. D., Treanor, M., \& Craske, M. G. (2019). Pilot for novel context generalization paradigm. Journal of Behavior Therapy and Experimental Psychiatry, 62, 49-56.

Miyatsu, T., Gouravajhala, R., Nosofsky, R. M., \& McDaniel, M. A. (2019). Feature highlighting enhances learning of a complex natural-science category. Journal of Experimental Psychology: Learning Memory and Cognition, 45(1), 1-16.

Mulder, J. M. (2018). The limits of humeanism. European Journal for Philosophy of Science, 8(3), 671-687.

Murtaeva, D. Z. (2015). Mirovozzrencheskij obraz v nauchnom poznanii. PhD dissertation. Ufa: Bashkir State University. (In Russian)

Norton, D. F., \& Norton, M. J. (2000). A Treatise of Human Nature: Being an Attempt to Introduce the Experimental Method of Reasoning Into Moral Subjects. Oxford University Press.

O'Connor, C. (2017). Evolving to Generalize: Trading Precision for Speed. The British Journal for the Philosophy of Science, 68(2), 389-410.

O'Connor, Z. (2015). Colour, contrast and gestalt theories of perception: The impact in contemporary visual communications design. Color Research \& Application, 40(1), 8592.
Phalke, A. R., \& Özdoğan, M. (2018). Large area cropland extent mapping with landsat data and a generalized classifier. Remote Sensing of Environment, 219, 180-195.

Rahmatullin, R. Yu. (2000). Ontologizirovannye obrazy v nauchnom poznanii: genesis I funkcii. Doctoral dissertation. Ufa: Bashkir State University (In Russian).

Rahmatullin, R. Yu. (2012). Germenevticheskaya funkciya obraza $v$ processeobucheniya, Vestnik Karagandinskogo universiteta, 4, 74-79 (In Russian).

Rahmatullin, R. Yu. (2017). Obraz kak component pedagogicheskogo prostranstva, Vestnik VEHGU, 2, 78-88 (In Russian).

Rakhimov, Z., Mudarisov, S., Gabitov, I., Rakhimov, I., Rakhimov, R., Farkhutdinov, I., Tanylbaev, M., Valiullin, I., Yamaletdinov, M., \& Aminov R. (2018). Mathematical Description of the Mechanical Erosion Process in Sloping Fields. Journal of Engineering and Applied Sciences, 13, 6505-6511.

Ram, H., Struyf, D., Vervliet, B., Menahem, G., \& Liberman, N. (2019). The Effect of Outcome Probability on Generalization in Predictive Learning. Experimental Psychology, 66(1), 2339.

Shoup, K. (2018). Particle Physics. Cavendish Square Publishing, LLC.

Stoletov, A. (2016). Social creativity and phenomenon of success in postindustrial society. Creativity Studies, 9(2), 141-150.

Stoletov, A. I. (2005). Tvorchestvo kak osnovanie lichnosti. Ufa: Bashkirskij gosudarstvennyj agrarnyj universitet (In Russian).

Suzuki, M. S. (2016). Rutherford scattering and hyperbola orbit Masatsugu Sei Suzuki and Itsuko S. Suzuki Department of Physics, SUNY at Binghamton (Date: June 15, 2016).

Thorpe, A., \& Figge, F. (2018). Climate change and globalisation as 'Double Exposure': Implications for policy development, Environmental Science \& Policy, 90, 54-64. 
Townsend, C., \& Ellis-Young, M. (2018). Urban population density and freeways in North America: A re-assessment. Journal of Transport Geography, 73, 75-83.

Webber, B. R., \& Davis, E. A. (2012).

Commentary on 'The scattering of $\alpha$ and $\beta$ particles by matter and the structure of the atom' by E. Rutherford (Philosophical Magazine
21 (1911) 669-688). Philosophical Magazine, 92(4), 399-405.

Żenczykowski, P. (2018). Quarks, Hadrons, and Emergent Spacetime. Foundations of Science, 24(2), 287-305.

Zinchenko, V. P. (1990). Nauka - neot"emlemaya chast' kul'tury? Russian Studies in Philosophy,1, 33-50 (In Russian). 